Gut, 1966, 7, 190

\title{
Internal anal sphincterotomy as an out-patient operation
}

\author{
H. R. MAGEE AND H. R. THOMPSON \\ From St. Mark's Hospital, London
}

EDITORIAL SYNOPSIS This is a valuable and practical article reviewing the results of internal anal sphincterotomy for fissure-in-ano under local anaesthesia as an out-patient procedure.

\section{PATHOLOGICAL BASIS FOR OPERATION}

An acute fissure when observed by everting the anus shows longitudinal muscle fibres in the floor of the ulcer. These are fibres of the conjoint longitudinal muscle layer which have passed downwards through the internal anal sphincter to gain attachment to the anal canal and perianal skin. If the lesion persists, the longitudinal fibres ulcerate through to expose the underlying whitish circular fibres of the internal sphincter. The edges are well defined and are undermined so that the true size of the ulcer is concealed. Infection is an important complication and its presence leads to the formation of the external skin tag and the hypertrophied anal papilla. The inflammation may progress to suppuration and the formation of a blind internal fistula, or rarely, it may track externally to form a complete low anal fistula. Division or stretching of the circular muscle fibres of the internal sphincter exposed in the floor of a fissure-in-ano relieves the pain characteristic of the lesion and results in healing.

\section{SELECTION OF PATIENTS}

Care must be taken in the selection of patients for operation in an out-patient department as some are temperamentally unsuited for any procedure under local anaesthesia. The presence of large internal haemorrhoids, a large skin tag and polyp, a chronic abscess or fistula, or social factors such as remoteness of the patient's home from the hospital are contraindications to operation in an out-patient department. Under these circumstances, the patient is admitted for treatment for $\mathbf{4 8}$ hours or longer.

\section{TECHNIQUE OF OPERATION}

The patient must have had his bowels open on the morning of operation. He lies on the couch in the left lateral position and the anal area is shaved and cleaned with cetavalon and spirit.

Xylocaine $1 \%$ containing adrenaline, $1 / 200,000$, is used as the local anaesthetic and a field block of the inferior haemorrhoidal nerves is administered as follows:

Using a $5 \mathrm{~cm}$. needle, a weal is raised $3 \mathrm{~cm}$. posterior to the anus. The needle is then directed forwards, laterally and slightly upwards, $10 \mathrm{ml}$. of the solution being injected on each side. Following this, a few millilitres of xylocaine are injected under the fissure using a fine (size 20) needle; and finally some amethocaine ointment is introduced into the anal canal.

After 10 to 15 minutes the area is sufficiently anaesthetized to permit the introduction of a bivalve speculum and for the operation to be carried out. Where the fissure is chronic and the muscle fibrosed it may not be possible to open the blades fully until the sphincter has been partially divided. In a posterior or postero-lateral fissure the muscle may be incised through the base of the lesion, but for those situated anteriorly, the wound should be made in the left postero-lateral quadrant. Dividing the sphincter through the base of an anterior fissure leaves a wound which heals slowly and is less effective in relieving pain. This is seen in women especially.

If a posterior tag is present it is excised, otherwise a small incision is made posteriorly for about $1.5 \mathrm{~cm}$. from the end of the fissure. With the points of the scissors it is possible to define a plane between the fibrous lower border of the internal sphincter and the longitudinal muscle layer and when this has been extended up to the level of the dentate line, the sphincter is cut and the edges of the wound trimmed. The smooth conjoint longitudinal muscle layer may now be seen; this layer must not be divided and the underlying fibres of the external sphincter muscle should not be exposed. 
If an enlarged anal papilla is present it is now excised, and it may also be necessary at this stage to sever a few of the commissural fibres of the subcutaneous external sphincter, should they be prominent, so that no ridges are left and the finger will pass smoothly into the anus. If a small blind internal fistula, or complete fistulous track is present, then this should be laid open.

The shape of the resulting raw area after sphincterotomy may be linear, elliptical, or triangular with the base outwards according to the circumstances.

During the operation, bleeding is usually slight and is easily controlled with pledgets of gauze soaked in adrenaline $1 / 1,000$. If small or moderate sized haemorrhoids are seen, they should be injected with $5 \%$ phenol in almond oil, for the complication of a prolapsed, thrombosed haemorrhoid is not uncommon. As the speculum is removed it will be seen that the anus is well relaxed, almost inviting any haemorrhoids to prolapse.

At the end of the operation a small piece of haemostatic gauze (Surgicel) is placed on the wound and covered with two small gauze dressings, one containing adrenalin $1 / 1,000$ and the other Bradosol $1 / 2,000$. These are kept in place by more gauze pads and a T-bandage. The patient rests for an hour and is then allowed to leave with instructions to go to bed after returning home. Codeine compound tablets are provided for relief of pain and also pethidine, $100 \mathrm{mg}$., to be taken by mouth on retiring to ensure a comfortable night.

The patient is advised not to open the bowels until the second post-operative day and to follow this with a warm bath. Dressings are supervised in the out-patient department on alternate days from the third day onwards, and the use of an anal dilator is encouraged after the fifth day.

Supervision is continued until healing has occurred.

\section{CLINICAL MATERIAL}

During the 24-month period from 1 January 1962 to 31 December 1963, 189 patients with fissure-inano were treated by sphincterotomy in the Outpatient Department, St. Mark's Hospital, the operation being carried out by seven resident surgical officers, and it has been possible to follow up 139 of these patients by questionnaire.

Forty-eight patients were not available for followup, having changed their address, and two were no longer alive.

Of the 139 who answered, 104 were males and 35 were females. The ages ranged from 18 to 69 years.

The questions asked were as follows:-

1 Do you have any pain on passing a motion?
2 Do you have perfect control of your bowel motions?

3 Do you have full control of wind?

4 Is the present control of wind any different to what it was before the operation?

5 Is soiling of the underwear a problem? If so, is it worse than before the operation?

6 Any remarks?

Fourteen patients who stated they had pain, or imperfect control of faeces, or who gave unsatisfactory answers, were interviewed.

\section{RESULTS}

TIME OF HEALING Time of healing varied between three and 12 weeks, but most seemed to have healed by the sixth week. One patient had an anterior fissure which made very little improvement after sphincterotomy (which had been carried out through the base of the fissure) and she was admitted five months later for posterior sphincterotomy under a general anaesthetic.

RELIEF OF PAIN Many people replied in the section inviting remarks that the operation was a success and were very grateful. Three per cent. of patients stated that they still had pain similar to that experienced before operation and on examination they were found to have recurrent fissures. Another $9 \%$ said that pain was slight or occurred only occasionally when the motion was hard.

IMPERFECTIONS OF FUNCTION Three per cent. of patients stated they had imperfect control of faeces and $17 \%$ said that control of flatus was imperfect. Twenty-nine per cent. noted that the present control appeared to be different to that before operation and just over one quarter of this latter group thought that there was some improvement in that flatus was easier to pass.

Soiling of the underwear occurred in $41 \%$ of patients. Twenty-two per cent. said it was worse and the remainder said it was the same or better. Two people thought it was better and one stated that it occurred only occasionally and then during heavy colds.

TABLE

SUMMARY OF RESULTS

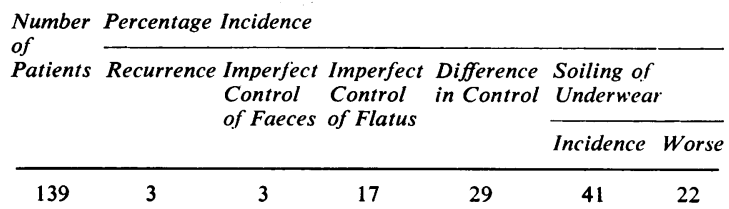




\section{DISCUSSION}

Anal fissure has been treated by various methods of division of the fibres of the internal anal sphincter. They may be ruptured by forcible stretching as first practised by Récamier, or divided surgically. This may be done by palpation after everting the anus (Miles' pectenotomy), or after a proctoscope has been inserted the muscle may be dissected out and divided under direct vision. This latter procedure is by far the most satisfactory as it can be carried out with greater accuracy and also it is possible to deal with any complications, such as a small abscess cavity, fistulous track, or internal haemorrhoids, should these be present.

The operation is usually carried out under general anaesthesia but it can be done under local anaesthesia in an out-patient department just as effectively and with comparable results. Recurrence rate in this series was $3 \%$. As not all patients are suitable for reasons stated earlier, care must be taken in their selection.

It should be stressed that for anterior fissures the wound should be made in the left postero-lateral quadrant, for division of the sphincter through the base of an anterior lesion heals very slowly, especially in women. One of the patients illustrates this point and she was admitted later for operation under a general anaesthetic. Other reasons for delay in healing are the presence of haemorrhoids and exuberant granulation tissue in the wound.

Graham-Stewart, Greenwood, and Lloyd-Davies (1961) have suggested that muscle spasm plays only a small part and may not be the main cause of failure to heal. They state that once a tear has occurred in the region of the pecten, re-opening of the fissure is likely each time a formed stool is passed. In their opinion 'sphincterotomy and stretching cause an effect which is far more important than the relief of spasm, namely, widening of the ring of skin in the pectinate portion of the anal canal. Sphincterotomy achieves this in the same way as an episiotomy; stretching, by sheer force, widens the ring and enlarges the fissure. After these procedures defaecation is not likely to cause stretching of the skin margin to its limit until time has allowed the fissure, the edges of which have been freshened, to heal'.

This opinion does not satisfy as an explanation for failure of healing.

A more probable explanation is based on the pathological anatomy of fissure-in-ano. It is known that the fissures that heal spontaneously are acute fissures. The longitudinal fibres of the conjoined longitudinal muscle are the only fibres seen in the base of such fissures. These fibres are inserted into the anal and perianal skin and consequently undermining of the edges of the fissure cannot and does not occur. In chronic fissures the longitudinal muscle fibres ulcerate through and are destroyed in the fissure area, leaving a space between the anal mucosa and the internal sphincter ani muscle. The edges of the fissure are now undermined at the sides and sometimes below. The fissure edges are held in close apposition, except at defaecation, by spasm of the sphincter muscles and, as a result, a small, chronic, imperfectly drained abscess is formed.

Sphincterotomy allows the cut ends of the internal sphincter muscle to retract under the anal mucosa, thus providing a channel of drainage for the abscess cavity.

In the same way, though less efficiently, paralysis of the sphincter muscles by stretching neutralizes the muscle spasm holding the two edges of the fissure together; drainage can now occur and again the fissure will heal. Healing also occurs in the same way after relieving muscle spasm by the injection of long-acting anaesthetics in oily solutions.

Minor defects in anal continence were noted by Bennett and Goligher (1962) after internal sphincterotomy and to a lesser extent after stretching of the anal sphincters. This series also shows that the operation has interfered with the control of faeces and flatus to some extent, minor degrees being evidenced by soiling of the underwear. It has been suggested that the role of the internal sphincter seems to be concerned with the refinements of anal continence and one of its functions is to maintain the basic or resting tone of the sphincter mechanism. It is perhaps the tonic contraction of this muscle alone or in conjunction with the external sphincter that imposes the initial brake on the passage of flatus or liquid faeces and gives the voluntary muscles time to contract. In this series soiling was present in $41 \%$ of patients and $22 \%$ stated that it was worse than before. This figure is similar to that in the series of Bennett and Goligher (1962) in which the incidence of unaccustomed soiling after sphincterotomy was $28 \%$.

\section{SUMMARY}

The technique of internal sphincterotomy as an out-patient procedure has been described and the results of operations in the Out-Patient Department at St. Mark's Hospital in 1962-1963 have been reviewed.

The operation is a satisfactory method of treatment of the condition in suitable patients although some defect in anal control may be found as an result.

A suggestion has been made to explain the reasons for healing of the lesion after operation. 
BIBLIOGRAPHY

Bennett, R. C., and Goligher, J. C. (1962). Results of internal sphincterotomy for anal fissure. Brit. med. J., 2, 1500-1503.

Brossy, J. J. (1965). Anatomy and surgery of anal fissure, with special reference to internal sphincterotomy. Ann. Surg., 144, 991-998.

Gabriel, W. B. (1930). The treatment of pruritus ani and anal fissure. Brit. med. J., 2, 311-312.

Graham-Stewart, C. W., Greenwood, R. K., and Lloyd-Davies, R. W. (1961). A review of 50 patients with fissure in ano. Surg. Gynec. Obstet., 113, 445-448.
Hughes, E. S. R. (1953). Anal fissure. Brit med. J., 2, 803-805.

Inberg, K. R. (1953). Partial internal sphincterotomy compared with some other methods in the treatment of anal fissure. Acto chir. scand., suppl., 183.

Lockhart-Mummery, H. E. (1957). Fissure-in-ano. In Operative Surgery, edited by C. Rob and R. Smith, vol. 3, pp. 11-13. Butterworth, London.

Morgan, C. N. and Thompson, H. R. (1956). Surgical anatomy of the anal canal. Ann. roy. Coll. Surg. Engl., 19, 88-114.

Watts, J. McK., Bennett, R. C., and Goligher, J. C. (1964). Stretching of anal sphincters in treatment of fissure-in-ano. Brit. med. $J$. 2, 342-343. 